\title{
Energetic analysis and development of a new recovery system from a combustion engine of a vehicle for cooling and storage of eutectic plates for drugs
}

\begin{abstract}
This manuscript represents an energetic analysis of a new system. This system is essentially based on the recovery of heat from the exhaust gas of a vehicle engine. The energy recovery has been achieved by the integration of two thermodynamic cycles; the Organic Rankine (ORC) cycle to produce electricity and the vapour compression cycle (VCC) to produce refrigeration. The first part of this study is devoted to describe the operating principle of this new system. The last part of this study presents the mathematical equations and the thermodynamic models to be used during this study.
\end{abstract}

Keywords: energy, combustion engine, eutectic plates, drugs, fuel, renewable energies
Volume 7 Issue 2 - 202I

\author{
Noureddine Toujani \\ Tunis El Manar University, Tunisia
}

Correspondence: Noureddine Toujani, Tunis El Manar

University, National School of Engineers (ENIT) of Tunis, Energy Research and Environment Unit, BP 37, Le Belvédère 1002 Tunis, Tunisia, Tel (+216) 502295 60,

Email toujeninoureddine@gmail.com

Received: March 30, 2021 | Published: April 30, 2021

\section{Introduction}

Since the industrial revolution, the way of life of Western societies has been inextricably linked with the presence of affordable and easily accessible energy. This model of "modern" and energyintensive civilization has since spread widely across the globe and continues to gain ground in developing countries today. This was made possible by an energy supply mainly provided by fossil fuels, to the point that these currently represent more than $80 \%$ of the world's primary energy production. But, because of the greenhouse gas emissions that it produces, this energy consumption, which has become gigantic and still growing on a global scale, is at the origin of climate change that must now be mitigated and which must be addressed. Adapt throughout this century. In this context of an everworsening environmental crisis, the energy transition appears to be the cornerstone of the fight against climate change and more generally as a centrepiece of sustainable development, at all levels, from local to global. In short, it is the centrepiece of a broader transition to a lowcarbon economy and society and sustainable lifestyles. On a global scale and in a context of triumphant modern civilization, the ultimate and urgent question concerns, not our ability to meet growing energy needs in the coming decades, but rather our ability to control energy consumption. (energy management, lifestyles, territorial organization, etc.) while developing as quickly as possible the share of "green" energies in our energy systems, to the point where they will become dominant, or even possibly the only ones. major forms of exploited energy resources. A large-scale energy transition therefore appears essential.

Nowadays, the world is confronted with multiple energy and environmental challenges, resulting from the growing need for fossil fuel which is becoming increasingly insufficient. The integration and exploitation of renewable energies is becoming vital, to meet energy needs both nationally and internationally. Among the renewable energy resources, with great potential for producing electricity and cooling, we cite solar energy, biomass, geothermal energy and waste heat from industry. Indeed, and in terms of energy production, several thermodynamic cycles can be considered. The most commonly used are the Rankine cycle, the Kalina cycle ${ }^{1,2}$ and the Gosswami cycle. ${ }^{3}$ According to the literature, the organic Rankine cycle remains the least complex and the most efficient. To this end, in recent years many researchers ${ }^{4-8}$ have been interested in the possibilities of improving the energy performance of these cycles. In particular, we mention the efforts of Baha Salah ${ }^{9}$ who published in 2007 a study emphasizing the importance of the choice of fluids for the organic Rankine cycle at low temperature. The results revealed in this investigation have shown that the working fluids best suited to Rankine cycles are R601, R600a, R600 and R245ca and that the corresponding thermal efficiency varies between 12 and $13 \%$. Another study developed by Wong $\mathrm{ZQ}^{10}$ made it possible to develop a thermophysical multi-parameter correlation function of each fluid in order to determine the most appropriate fluid in the ORC cycle. He found that R123 is the most efficient in terms of thermal efficiency for generator heat, and this for varying temperatures between 100 and $180^{\circ} \mathrm{C}$. On the other hand, for a temperature above $180^{\circ} \mathrm{C}, \mathrm{R} 146$ is rather the most appropriate. In this paper we are interested in integrating the ORC cycle in a vehicle in order to recover the heat coming from an engine and to valorize in term energy to produce cold and keep the eutectic plates of drugs.

\section{Engine case study: technical characteristics and thermal flow of a heat engine}

The objective of this study (Figure 1) is to use the exhaust gases of a heat engine to produce electricity and refrigeration. The choice of engine model and its characteristics is very important on the performance of our new system. For this, presenting us with technical details and physical characteristics of our study engine. We want to integrate at the end of the exhaust gas an ORC cycle to produce electricity and a VCC cycle to produce refrigeration. The temperature of which is raised from 600 to $1500^{\circ} \mathrm{C}$ approximately. As soon as the fuel is injected (sprayed), it ignites almost instantly, without the need for spark plug ignition. By burning, the mixture strongly increases the temperature and the pressure in the cylinder (60 to 100 bars), pushing 
back the piston which provides a working force on a connecting rod, which drives the rotation of the crankshaft (or crank shaft acting as an engine axis, see connecting rod-crank system).

The four times of the Diesel cycle are:

I. Admission: air through the opening of the intake valve and the descent of the piston.

II. Compression: air by rising the piston, with the inlet valve closed.

III. Engine time: shortly before top dead center, fuel is introduced by injection, which mixes with compressed air. The rapid combustion that follows constitutes engine time, the hot gases pushing back the piston, releasing part of their energy. This can be measured by the motor power curve;

IV. Exhaust: gases burnt by the opening of the exhaust valve, pushed by the rise of the piston.

The rotational speeds of diesel engines are very different from one engine to another. In fact, the bigger the engine, the greater the piston stroke, and the slower the engine. Three classes of engines are thus defined:

1. Slow motor: less than 200rpm.

2. Semi-fast motors: between 400 and 1000rpm.

3. Fast motor: 1000rpm and more.

The maximum speed limit of an engine is determined by the speed of movement of the piston in the cylinder.

The engine manufacturers, depending on the use of the engine and the reliability required of them, have set the following limit ranges (result of wear tests):

Fixed engine (generator, large boat engine): 6 to $8 \mathrm{~m} / \mathrm{s}$.

1) Heavy-duty engine: 8 to $9 \mathrm{~m} / \mathrm{s}$.

2) Automotive engine: 12 to $13 \mathrm{~m} / \mathrm{s}$.

3) Competition engine: over $15 \mathrm{~m} / \mathrm{s}$.

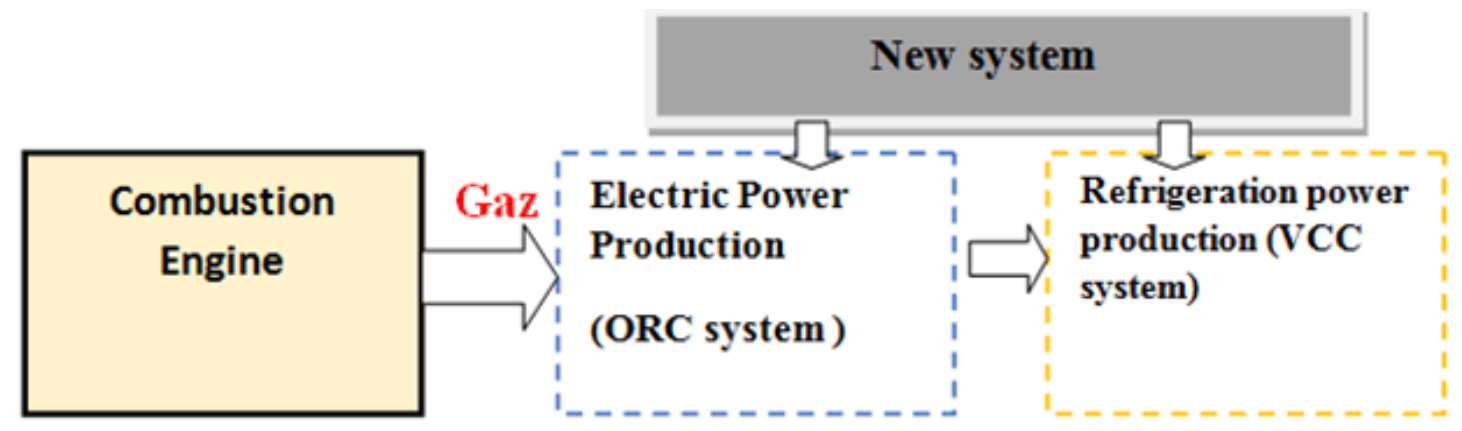

Figure I Planned energy conversion chain.

Figure 2 shows the distribution of different engine power study namely mechanical power, thermal power and escape to the outside is formed of smoked.

The Characteristics of exhaust gases for a light vehicle (gasoline engine):

a) Temperature between 400 and $800^{\circ} \mathrm{C}$ b) Mass flow rate of around $100 \mathrm{~kg} / \mathrm{h}$

c) Composition: $\mathrm{CO}, \mathrm{HC}, \mathrm{NO}$, etc.

d) Composition: $\mathrm{CO} 2, \mathrm{HC}$, NOX, etc.

e) Average heat capacity: $1150 \mathrm{~J} / \mathrm{kg} . \mathrm{K}$

Gasoline engine hotter than diesel engine but lower flow rate.

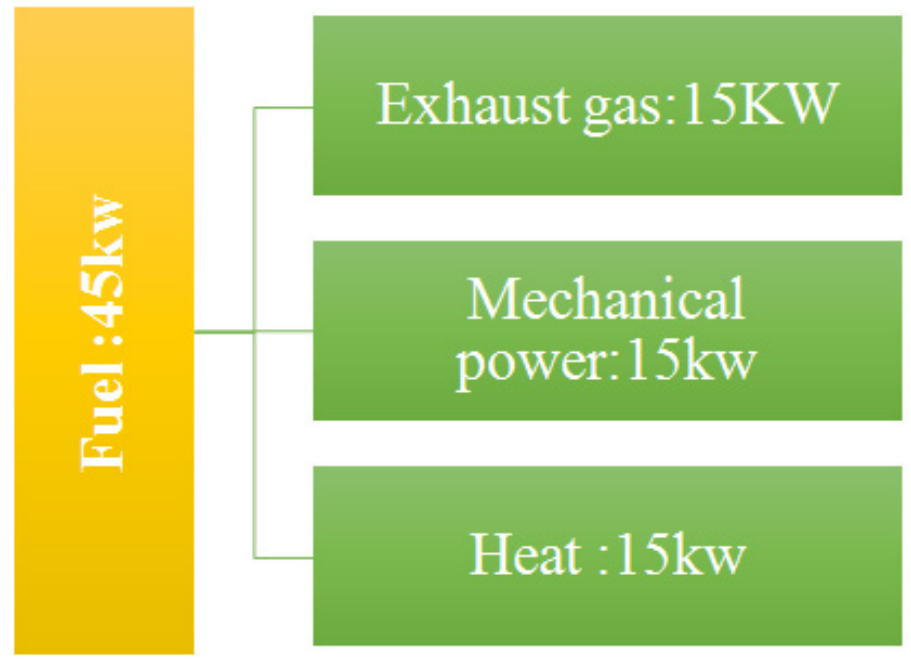

Figure 2 Distribution of different engine power study. 


\section{System description}

Figure 3 shows the operating principle of our thermodynamic cycle. This new system is made up of three units.

\section{Unit1: Recovery system}

\section{Unit 2: Electric power production}

\section{Unit3: Refrigeration Power production}

The first unit (Unit1) consists of recovering the heat here from the combustion engine of a vehicle using a heat exchanger. The latter presents the engine hot source where its internal fluid (water) will be vaporized. this steam will be fed to our turbine to operate it, as an energy gain at the output of this engine, we receive a mechanical work of $1 \mathrm{~kW}$ on the drive shaft that we must then convert it into electricity by the ORC cycle and refrigeration by the VCC cycle.

First, the fume given off by the combustion engine enters a recuperate exchanger. In fact, thanks to a heat exchange in the exchanger between fluid 1 (smoked) and fluid 2 (heat transfer fluid), heat recovery is carried out and fluid 2 will be heated. This phase represents the heating and vaporization phase. It suffices for the fluid 2 to reach the desired hot temperature, immediately will have entered a separator to eliminate all the water droplets (problem of oxidation of the organs), then will be passed into a micro-turbine, this is the phase of relaxation, this organ is used to convert thermal energy into mechanical work (rotation of the axis), then this work will be converted into electricity by an alternator. After the expansion the fluid goes to the condensation phase, the fluid condenses by a condenser to make the fluid liquid. Finally since our cycle is closed, a pump has been integrated to make the recirculation it is the pumping phase. The cycle that we described above is the Organic Rankine Cycle (ORC). Unit 3 represents the refrigeration circuit; it is the reverse cycle of the ORC which is used to produce the cold. This area includes a thermal compressor, its role is to compress the gaseous fluid, a condenser to make the condensation, an expansion valve for expansion and lower the working pressure and an evaporator to produce cold. This cycle is called: compression steam cycle, it needs an electrical source at the compressor level to operate. For this we are going to dedicate a part of the electrical voltage ends by the ORC central for the VCC cycle.

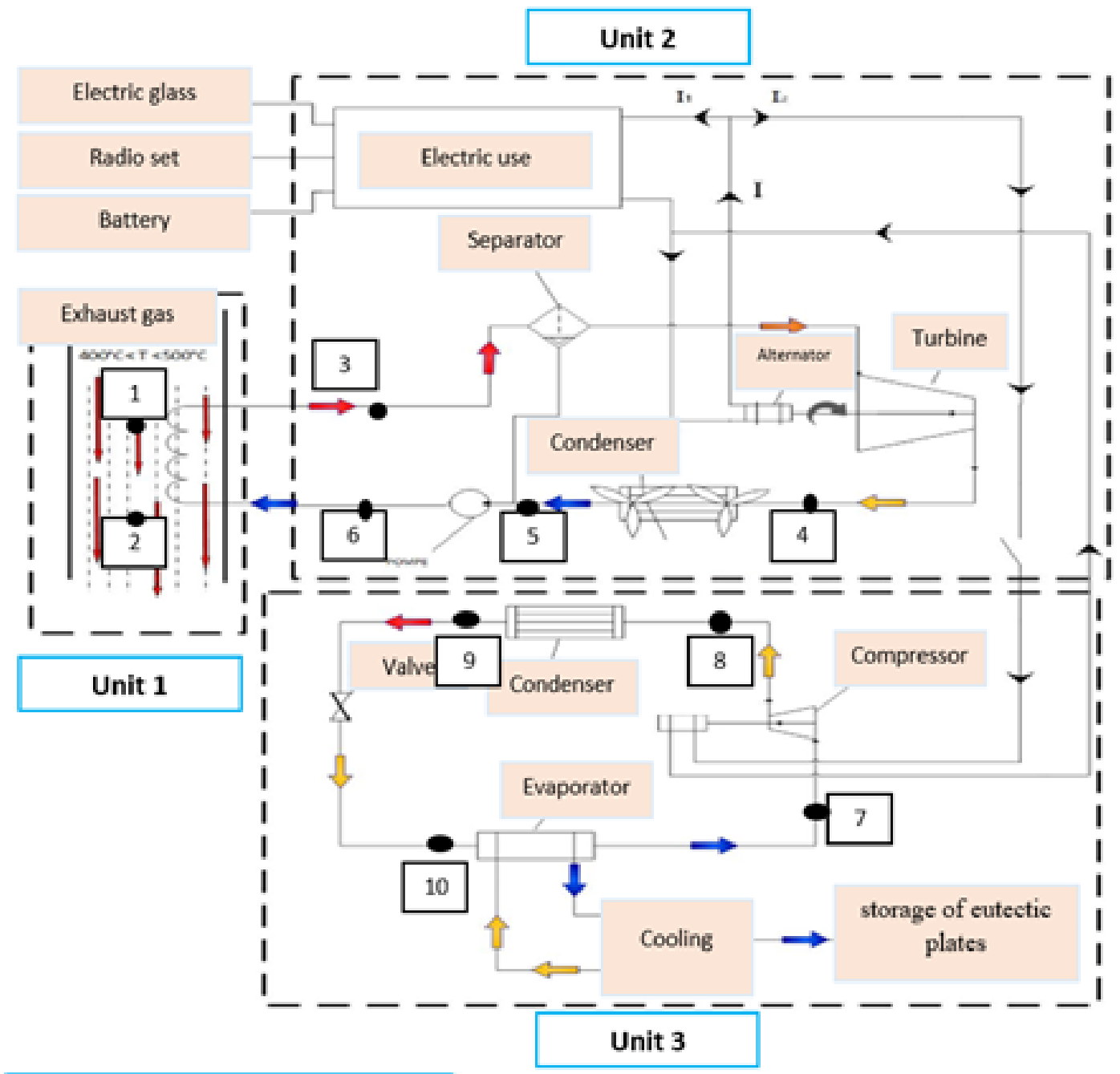

Unit 1 : Recovery unit

Unit 2 : Electric Power

Unit 3 : Refrigeration Power

Figure 3 Thermodynamic cycle.

Citation: Toujani N. Energetic analysis and development of a new recovery system from a combustion engine of a vehicle for cooling and storage of eutectic plates for drugs. Int J Biosen Bioelectron. 2021;7(2):64-67. DOI: 10.15406/ijbsbe.2021.07.00213 


\section{Assumptions}

To develop thermodynamic models and perform the analysis, the following assumptions were made:

a. The frictional and the heat losses in the system were considered negligible.

b. The kinetic and potential energy aspects were ignored.

c. the condensation and evaporation process were considered to be isobar

d. The process through the throttling valve of the state 10-11 was considered to be isenthalpic.

e. The condensation temperature at state 7 (refer to Figure 2) was fixed $\mathrm{t} 25^{\circ} \mathrm{C}$, for all of the working fluids.

f. The pinch point difference in all the heat exchangers is considered to be approximately $10^{\circ} \mathrm{C}$.

g. The isentropic efficiencies of the pump, expander and the compressor have a value of $80 \%$.

h. saturated states are assumed at the boiler and condenser outlets.

\section{Mathematic and thermodynamic models}

The turbine (T1) output power $\dot{\mathrm{W}}_{\mathrm{t} 1}$ is calculated by the following equation:

$$
\dot{\mathrm{W}}_{\mathrm{t} 1}=\dot{\mathrm{m}}_{1}\left(\mathrm{~h}_{3}-\mathrm{h}_{4 \mathrm{a}}\right)=\dot{\mathrm{m}}_{1}\left(\mathrm{~h}_{3}-\mathrm{h}_{4 \mathrm{~s}}\right) \eta_{\mathrm{t}}
$$

The required power for the pump $\left(\mathrm{W}_{\mathrm{p}}\right)$ is calculated by the following equation:

$$
\dot{\mathrm{W}}_{\mathrm{P}}=\dot{\mathrm{m}}_{1}\left(\mathrm{~h}_{6 \mathrm{a}}-\mathrm{h}_{5}\right)=\frac{\dot{\mathrm{m}}_{1}\left(\mathrm{~h}_{6 \mathrm{~s}}-\mathrm{h}_{5}\right)}{\mathrm{c}_{\mathrm{P}}}
$$
as:

The rate of heat added to the working in the recovery $\dot{Q}_{b}$ is defined

$$
\dot{\mathrm{Q}}_{\mathrm{b}}=\dot{\mathrm{m}}_{1}\left(\mathrm{~h}_{3}-\mathrm{h}_{6 \mathrm{a}}\right)=\dot{\mathrm{m}}_{2}\left(\mathrm{~h}_{1}-\mathrm{h}_{2}\right)
$$

The rate of heat removed from the working in the condenser $\left(Q_{c}\right.$ ) is defined as:

$$
\dot{\mathrm{Q}}_{\text {cond }}=\dot{\mathrm{m}}_{1}\left(\mathrm{~h}_{5}-\mathrm{h}_{4}\right)
$$

The thermal efficiency $\left.\left(\eta_{\mathrm{ORC}}\right)\right)$ is described as:

$$
\eta_{\mathrm{ORC}}=\frac{\dot{\mathrm{W}}_{\mathrm{t}}-\dot{\mathrm{W}}_{p}}{\dot{\mathrm{Q}}_{\mathrm{b}}}
$$

The net system output power $\dot{\mathrm{W}}_{\text {net }}$ is defined as:

$$
\dot{\mathrm{W}}_{\text {net }}=\dot{\mathrm{W}}_{\mathrm{t}}-\dot{\mathrm{W}}_{\text {comp }}-\dot{\mathrm{W}}_{\text {pump }}
$$

The overall system performance $\left(\mathrm{COP}_{\mathrm{S}}\right)$ is defined as:

$$
\mathrm{COP}_{\mathrm{S}}=\frac{\dot{\mathrm{Q}}_{\mathrm{ev}}+\text { Wnet }}{\dot{\mathrm{Q}}_{\mathrm{b}}}
$$

The required power for the compressor $\dot{\mathrm{W}}_{\text {comp }}$ can be calculated by the following equation:

$$
\dot{\mathrm{W}}_{\text {comp }}=\dot{\mathrm{m}}_{3}\left(\mathrm{~h}_{8}-\mathrm{h}_{7}\right)=\frac{\dot{\mathrm{m}}_{5}\left(\mathrm{~h}_{8}-\mathrm{h}_{7 \mathrm{~s}}\right)}{\mathrm{c}_{\text {comp }}}
$$

The refrigeration capacity of the evaporator $\dot{\mathrm{Q}}_{\mathrm{eva}}$ is calculated by the following equation:

$$
\dot{\mathrm{Q}}_{\mathrm{eva}}=\dot{\mathrm{m}}_{3}\left(\mathrm{~h}_{7}-\mathrm{h}_{10}\right)
$$

\section{Acknowledgments}

None.

\section{Conflicts of interest}

The authors declare that there is no conflict of interest.

\section{References}

1. Deepaka K, Guptab AVSSKS. Thermal Performance of Geothermal Power Plant with Kalina Cycle System. International Journal of Thermal Technologies. 2014.

2. Shankar Ganesh N, Tangellapalli. Processes development for high temperature solar thermal Kalina power station. Thermal Science. 2014;18(2):S393-S404.

3. Marin C, Goswami DY. Effectiveness of cooling production with a comhincd power and cooling thermodynamic cycle. Applied Thermal Engineering. 2006;26(5-6):576-582.

4. Casartelli D, Binotti M, Silva P, et al. Power block off-design control strategies for indirect solar ORC cycles. Energy Procedia. 2015;69:12201230.

5. Sylvain Quoilin, Martijn Van Den Broek, Se'bastienDeclaye, et al. Techno-economic survey of Organic Rankine Cycle (ORC) systems. Renewable and Sustainable Energy Reviews. 2013;22:168-186.

6. Villarini M, Bocci E, Moneti M, Di et al. State of art of small scale solar powered ORC systems: a review of the different typologies and technology perspectives. Energy Procedia. 2014;45:257-267.

7. Wang EH, Zhang HG, Fan BY, et al. Study of working fluid selection of organic Rankine cycle (ORC) for engine waste heat recovery. Energy. 2011;36(5):3406-3418.

8. WANG Zhiqi, ZHOU Naijuna, Guo Jjng. Performance analyjsis of ORC power generation system with low-temperature waste heat of aluminum reduction cell. Physics Procedia. 2012;24:546-555.

9. Bahaa Saleh, Gerald Koglbauer, Martin Wendland, et al. Working fluids for low-temperature organic Rankine cycles. Energy. 2007;32:1210-1221.

10. Wanga ZQ, Zhou NJ, Guo J, et al. Fluid selection and parametric optimization of organic Rankine cycle using low temperature waste heat. Energy. 2012;40:107-115 